\title{
Construct Validation of the Inventory of Learning Processes
}

\author{
R. R. Schmeck \\ Southern Illinois University \\ F. D. Ribich \\ Wartburg College
}

Two correlational investigations are described which are aimed at establishing the construct validity of the dimensions assessed by the scales of the Inventory of Learning Processes. The SynthesisAnalysis scale is assumed to assess "deep" (e.g., semantic) information-processing habits. It was positively related to critical thinking ability, curiosity, and both independent and conforming achievement-striving behaviors but negatively related to anxiety. The Study Methods scale is assumed to assess the habits of promptly completing all assignments, attending all classes, and generally "studying" a lot. It was positively related to curiosity and conforming types of achievement striving and negatively related to critical thinking ability. The fact that critical thinking ability is related positively to SynthesisAnalysis and negatively to Study Methods suggests that students with low critical thinking ability but high achievement motivation might substitute conventional repetitive study for "deep processing" because they find it difficult to engage in "deep processing." The Fact Retention scale is assumed to assess attention to and proneness to retain detailed, factual information. It was positively related to conforming achievement behaviors and negatively related to anxiety. The Elaborative Processing scale is assumed to assess the habit of restating and reorganizing information so as to relate it to one's own experiences. It was positively related to mental imagery ability and curiosity.

APPLIED PSYCHOLOGICAL MEASUREMENT

Vol. 2, No. 4 Fall 1978 pp. 551-562

(c) Copyright 1978 West Publishing Co.
Schmeck, Ribich, and Ramanaiah (1977) described five studies concerned with the development and preliminary validation of the Inventory of Learning Processes. The approach to the construction of this instrument incorporated those concepts and processes currently investigated in the areas of human information processing and memory (e.g., imagery, organization, depth of processing, and rehearsal strategies). In order to ask college students about these processes, statements were phrased relevant to learning processes in terms of the stimuli and activities of the typical academic setting. Factor analysis was used to determine the major dimensions underlying the learning processes statements and resulted in four scales having acceptable test-retest and internal consistency reliabilities.

The Synthesis-Analysis scale was assumed to deal with the amount of time and energy that the individual was willing to devote to making semantic or categorical judgments regarding new information. In this sense, the dimension assessed by the scale appeared similar to Craik's (1977) concept of depth (or level) of processing. Craik (1977) stated that "preliminary or shallow analyses are concerned with physical aspects of the stimulus, whereas subsequent, deeper analyses are concerned more with meanings and associative relationships" (p. 680). A very similar process has been observed by Marton and Saljo 
(1976) while analyzing the reports of students actually engaged in learning. Scores on the Synthesis-Analysis scale were positively related to performance on prose and verbal learning tasks, note-taking efficiency, college gradepoint-average, and ACT scores (Ribich, 1976; Schmeck, Ribich, \& Ramanaiah, 1977; Schmeck \& Grove, 1978).

The Elaborative Processing scale was assumed to assess the extent to which an individual is willing to translate new information into personal mediators, images, and examples and to fit it into a personal organizational framework. The dimension assessed by the scale appeared similar to Craik's (1977) concept of elaboration of encoding, which refers to the richer (i.e., more complex, more extensive) information processing which can occur at any given level of processing. Likewise, Elaborative Processing seems similar to Craik and Lockhart's (1972) Type II rehearsal, which differs from Type I rehearsal in that it is more elaborative and less repetitive. Weinstein $(1975,1977)$ has been working with a similar dimension in the context of academic study. Scores on this scale were positively related to lecture-learning, verbal-learning, and subjective organization ( $\mathrm{Ri}$ bich, 1976; Schmeck, Ribich, \& Ramanaiah, 1977)

Individuals earning high scores on the Study Methods scale review regularly, read all assignments, attend all lectures, and generally "study" a lot. Unfortunately, as Craik and Tulving (1975) have noted, intent to learn is not always a sufficient nor, for that matter, even a necessary condition for the occurrence of learning. Using the terminology of Craik and Lockhart (1972), it could be stated that one might engage in a great deal of Type I (i.e., simple repetitive) rehearsal with little improvement in retention; however, a small amount of Type II (i.e., elaborative) rehearsal might produce a considerable increase in retention. The important question is, "What does the student do with the information?" The authors would expect individuals who earn high scores on Synthesis-Analysis and Elaborative Processing (i.e., those who encode "deeply" and "richly") to retain information and score high on course examinations even if they earn a low score on the Study Methods scale. Indeed, Ribich (1976) and Schmeck and Grove (1978) have reported that Synthesis-Analysis is positively related to prose retention, college gradepoint-average, and ACT examination scores; but the Study Methods scale is not related to any of these measures.

The Fact Retention scale is assumed to measure an individual's propensity for storing detailed, factual information-the type of information called for on many objective tests. Thus, it is not surprising that scores on this scale were positively related to objective test performance (Ribich, 1976; Schmeck, Ribich, \& Ramanaiah, 1977) and to college grade-pointaverage and ACT examination scores (Ribich, 1976; Schmeck \& Grove, 1978). Also, the assumption that high scores on the scale indicate attention to details and specifics received mild support from the finding of a -.22 correlation between scores on the Fact Retention scale (Schmeck, Ribich, \& Ramanaiah, 1977) and on Pettigrew's (1958) Category Width Scale, indicating that those who score high on Fact Retention show a tendency to organize information into narrow (specific) categories.

The importance of laboratory studies of the type reported by Schmeck, Ribich, and Ramanaiah (1977) and Ribich (1976) should not be underestimated; but such studies take a great deal of time and are often more interpretable if they are preceded by studies which compare the instrument to other paper-and-pencil instruments. The two studies reported in the present paper approached the problem of construct validation by relating scores on the Inventory of Learning Processes to measures of critical thinking and cognitive preference (Study 1) as well as to imagery, anxiety, academic curiosity, and achievement motivation (Study 2). 


\section{STUDY 1}

The Inventory of Learning Processes was administered in combination with the WatsonGlaser Critical Thinking Appraisal (Watson \& Glaser, 1964) and the Cognitive Preference Test (Williams, 1975). The rationale for including the Critical Thinking Appraisal was the assumption that the Synthesis-Analysis scale assesses the activity of making semantic or categorical judgments regarding information. The concept of judgment and the attendant evaluation element suggested that those who score high on the Synthesis-Analysis scale would be likely to possess some minimum amount of critical thinking ability. Thus, a moderate positive correlation was predicted between the Critical Thinking Appraisal and the Synthesis-Analysis scale. No predictions were made regarding the relationship of critical thinking ability to the other scales of the Inventory of Learning Processes.

The Cognitive Preference Test was designed by Williams (1975) to determine whether or not an individual has a preference for dealing with information which consists mostly of facts, principles, or applications. In the present study, it was predicted that those who score high on the Fact Retention scale of the Inventory of Learning Processes would also tend to earn high scores on the Fact subscale of the Cognitive Preference Test. Similarly, it was expected that those who earn high scores on Elaborative Processing would score high on the Application, and possibly on the Principle, subscales of the Cognitive Preference Test.

\section{Method}

\section{Subjects}

The sample consisted of 54 volunteers (27 males and 27 females) from the Introductory Psychology course at Southern Illinois University. Volunteer participation as subjects was one of several different ways in which students could earn extra credit in the course.
Inventory of Learning Processes. This inventory is described by Schmeck, Ribich, and Ramanaiah (1977). It consists of 62 true-false statements concerned with behaviors which students might engage in while learning within the academic environment. The inventory contains four scales: Synthesis-Analysis (18 items); Study Methods (23 items); Fact Retention (7 items); and Elaborative Processing (14 items). All scales have demonstrated acceptable reliabilities (Schmeck, Ribich, \& Ramanaiah, 1977).

\section{Watson-Glaser Critical Thinking Apprais-} al. This test consists of a series of exercises which require the application of some of the important abilities involved in critical thinking (Watson \& Glaser, 1964). Form Ym was used in the present study. The test consists of five subtests: Inference ( 20 items; split-half reliability $=$ .60); Recognition of Assumptions (16 items; split-half reliability $=.74$ ); Deduction ( 25 items; split-half reliability $=.53)$; Interpretation $(24$ items; split-half reliability $=.67$ ); Evaluation of Arguments (15 items; split-half reliability $=.62$ ). The manual suggests that the total WatsonGlaser score (split-half reliability $=.87$ ) is most useful, but data concerning the separate scales is included in the present report.

The Cognitive Preference Test. Williams (1975) prepared 90 triads of items which give subjects a piece of scientific, mathematical, or social studies information as a stimulus and then have them assign an independent rating to each of the 3 pieces of additional information, indicating on a 5-point scale the likelihood that each piece of information would "occur" to them. These additional pieces of information fall in one of three categories: fact, principle, or application. For purposes of the present study, items from all three subject areas (science, math, and social studies) were combined to yield three scale scores: Fact, Principle, and Application. Since the scales are not ipsative, it is possible for a subject to score high on all three of them. Testretest reliabilities range from .81 to .89 . 


\section{Procedure}

Students were run in two sessions. During the first session, they completed the Inventory of Learning Processes and then the Cognitive Preference Test. The second session was held one week later; at that time the students completed the Watson-Glaser Critical Thinking Appraisal using the procedure recommended in the test manual (Watson \& Glaser, 1964). In addition, students were "debriefed" at the end of the second session (i.e., given a description of the purpose of the study and given an opportunity to ask questions concerning the goals and procedures of the study).

\section{Results and Discussion}

Since separate analyses for males and females revealed no sex differences, only the combined analysis will be reported. Table 1 presents intercorrelations between the scales of the Inventory of Learning Processes and the subscales of the Watson-Glaser Critical Thinking Appraisal. It was predicted that there would be a moderate positive correlation between Synthesis-Analysis and the Watson-Glaser; this prediction receives

support from the analysis summarized in Table $1(r=.33)$. Table 1 also reveals that SynthesisAnalysis was related mainly to the Deduction and Interpretation subscales of the Critical Thinking Appraisal.

A rather surprising result appearing in Table 1 is the significant negative correlation between Study Methods and critical thinking ability $(r=$ -.34). The relationship occurred mainly in the case of the Deduction, Interpretation, and Evaluation of Arguments subscales of the Critical Thinking Appraisal. Taken together, the positive correlation with Synthesis-Analysis and the negative correlation with Study Methods indicate that as critical thinking ability decreases, the probability that an individual will place an emphasis on traditional repetitive "study" increases, and the probability that he or she will engage in the activities assessed by the Synthesis-Analysis scale decreases. It is interesting to speculate that students who are motivated to achieve but are low on critical thinking ability have difficulty with the activities assessed by the Synthesis-Analysis scale and thus rely more heavily upon the simple repetitive study procedures assessed by the Study Methods scale.

Table 1

Intercorrelations Among the Scales of the Inventory of Learning Processes and the Watson-Glaser Critical Thinking Appraisal

\begin{tabular}{|c|c|c|c|c|c|c|}
\hline \multirow[b]{2}{*}{$\begin{array}{c}\text { ILP } \\
\text { Scales } \\
\end{array}$} & \multicolumn{6}{|c|}{ Watson-Glaser Critical Thinking Appraisal } \\
\hline & Inference & $\begin{array}{l}\text { Recogni- } \\
\text { tion of } \\
\text { Assump. }\end{array}$ & Deduction & $\begin{array}{c}\text { Interpre- } \\
\text { tation } \\
\end{array}$ & $\begin{array}{c}\text { Evaluation } \\
\text { of Argu- } \\
\text { ments }\end{array}$ & Total \\
\hline Synthesis- & & & & & & \\
\hline $\begin{array}{l}\text { Analysis } \\
\text { Study }\end{array}$ & .22 & .03 & $.34 * *$ & $.39 * *$ & .10 & $.33 * *$ \\
\hline $\begin{array}{l}\text { Methods } \\
\text { Fact }\end{array}$ & .07 & -.22 & $-.27 *$ & $-.32 * *$ & $-.30 *$ & $-.34 * \div$ \\
\hline $\begin{array}{l}\text { Retention } \\
\text { Elaborative }\end{array}$ & .08 & .03 & .11 & -.08 & .00 & .05 \\
\hline Processing & .08 & .07 & .26 & .17 & -.09 & .18 \\
\hline
\end{tabular}


Table 2

Intercorrelations Among the Scales of the Inventory of Learning Processes (ILP) and the Cognitive Preference Test (CPT)

\begin{tabular}{|c|c|c|c|c|}
\hline \multirow[b]{2}{*}{ Scale } & & \multicolumn{3}{|c|}{ Cognitive Preference Test } \\
\hline & & Fact & Principle & Application \\
\hline \multicolumn{5}{|l|}{ ILP Scales } \\
\hline Synthesis-Analysis & - & .15 & .06 & .00 \\
\hline Study Methods & & .10 & .21 & .24 \\
\hline Fact Retention & & .14 & .03 & .02 \\
\hline Elaborative Processing & & .24 & $.30 *$ & $.32 *$ \\
\hline \multicolumn{5}{|l|}{ CPT Scales } \\
\hline Principle & & $.73 * *$ & & \\
\hline Application & & $.56 * *$ & $.83 * *$ & \\
\hline
\end{tabular}

$\overline{* p}<.05 ; * *_{p}^{*}<.001$

In regard to the Cognitive Preference Test, since differential relationships were predicted between the scales of the Inventory of Learning Processes and the three scales of the Cognitive Preference Test, the relationships among the cognitive preference scales themselves were analyzed (last two rows of Table 2). These interrelationships are so high as to call into question any attempt within the present study to interpret differential relationships between these scales and the scales of the Inventory of Learning Processes. Nevertheless, the relationships between the two inventories are presented in Table 2. Indeed, there were significant positive relationships between Elaborative Processing and the Principle and Application scales of the Cognitive Preference Test. No other relationships were significant.

\section{STUDY 2}

This study was concerned with the relationships between the scales of the Inventory of Learning Processes and measures of imagery, anxiety, academic curiosity, and achievement motivation. The Elaborative Processing scale is assumed to assess the process of translating information into personally relevant mediators, images, and examples, and generally placing the information into a personally relevant organizational framework. Ribich (1976) reported a positive correlation between Elaborative Processing and one measure of elaboration, i.e., "subjective organization" (Tulving, 1962). The present study examined the relationship between Elaborative Processing and another elaborative technique, i.e., mental imagery (Paivio, 1971). It was expected that those who score high on the Elaborative Processing scale would generally have some minimum amount of imagery ability (this is similar to the earlier discussion of the relationship between Synthesis-Analysis and critical thinking ability). Thus, a moderate but significant positive correlation was expected between the Elaborative Processing scale and measures of imagery ability. No other relationships were anticipated between the Inventory of Learning Processes and imagery ability.

The rationale for including measures of anxiety was based on a study by Schwartz (1975) which provided evidence that the memory of high-arousal subjects tends to be organized around superficial, physical aspects of verbal material and the memory of low-arousal subjects is more likely to be organized around the semantic aspects of the material. Since the authors assumed that individuals who scored high on Synthesis-Analysis would carefully attend to se- 
mantic organization, it was predicted that the Synthesis-Analysis scale would correlate negatively with measures of arousal (i.e., two anxiety tests). No predictions were made regarding the relationship between the anxiety measures and the other three scales of the Inventory of Learning Processes.

The present investigation also employed an assessment of curiosity. Maw and Maw (1961) found $50 \%$ more retention of novel information in more curious subjects; this finding suggested that curious subjects were more prone to attend to and to process novel stimuli. In a similar vein, Johnson (1974) suggested that curious individuals would make more frequent and more effective use of their storage control processes (i.e., organization, encoding, rehearsal). Thus, it was expected that the Scale of Academic Curiosity would be positively correlated with Synthesis-Analysis (organization), Study Methods (information search and rehearsal), and Elaborative Processing (encoding).

The Achievement-via-Conformance and Achievement-via-Independence scales of Gough's (1957) California Psychological Inventory were also included in the present study. Domino $(1968,1971)$ reported that students high on Achievement-via-Independence perform best in classes which emphasize ideas, discussion, and independent thinking. Since these are the same activities attributed to individuals who score high on the Synthesis-Analysis and Elaborative Processing scales, it was predicted that these scales would correlate positively with the Achievement-via-Independence scale. Likewise, Domino $(1968,1971)$ reported that students high on Achievement-via-Conformance performed best in courses emphasizing memorization, lecture, and structured, rule-regulated learning. Since it was assumed that such activities typify individuals who score high on Study Methods and Fact Retention, a positive relationship was expected between the Achievement-via-Conformance scale and these two Inventory of Learning Processes scales.

\section{Method}

\section{Subjects}

The sample consisted of 100 undergraduate volunteers ( 32 males and 68 females) from the Southern Illinois University Introductory Psychology course. Students received course credit for participating in the study.

\section{Materials}

The Inventory of Learning Processes. The inventory employed in this study was identical to that employed in Study 1.

Betts Questionnaire Upon Mental Imagery. The shortened form of the inventory prepared by Sheehan (1967) was used as a measure of imagery in the following modalities: vision, audition, cutaneous sense, kinesthesis, taste, olfaction, and organic sense. Betts' original questionnaire contained 150 items, but Sheehan (1967) developed a 35-item version which is highly correlated $(r=.98)$ with the original questionnaire. Items require subjects to imagine a stimulus situation and then describe the clarity of the image on a 7-point scale.

Imagery Rating Scale. This instrument was developed by the present authors as an alternative measure of imagery. The scale requires subjects to rate the amount of imagery aroused by each of 15 words. The 15 words were chosen from the norms constructed by Paivio, Yuille, and Madigan (1968) to contain 5 words each from the high-, medium-, and low-imagery categories. Ratings were done on a 7-point scale. No reliability data were available.

Manifest Anxiety Scale. Taylor (1953) designed this scale to measure anxiety as defined by Cameron (1947). It is composed of 50 truefalse items. Test-retest reliabilities reported for the scale fall in the .80 to .89 range. It is assumed that the Manifest Anxiety Scale assesses emotional responsiveness, which contributes to the general drive level of the individual. 
Text Anxiety Questionnaire. Mandler and Sarason (1952) designed this scale to measure anxiety of a more situation-specific variety. The questionnaire is composed of 37 items concerning the individual's reactions to group intelligence tests, course examinations, and individual intelligence tests. Split-half reliability for the scale is reported to be .91 .

Scale of Academic Curiosity. This instrument was developed and further refined by Vidler and Rawan (1974, 1975). The final version is composed of 45 true-false items which deal with information-seeking behaviors and other behaviors generally indicative of curiosity in the academic setting. Vidler and Rawan (1975) did not report the reliability of the final version of the inventory, but data gathered in the present study indicated an internal consistency (KR-20) reliability of .80 .

Achievement-via-Independence and Achievement-via-Conformance scales of the Califormia Psychological Inventory. These scales were developed by Gough (1957) to assess motivation for achievement in two different settings. The Achievement-via-Independence scale contains 32 items having a test-retest reliability variously reported to be .57 to .71 . The scale is designed to assess factors which facilitate achievement in any setting where autonomy and independence are positive behaviors. The Achievement-viaConformance scale contains 38 items having a test-retest reliability reported to range from .60 to .79. This scale is designed to assess those factors which facilitate achievement in any setting where conformance is a positive behavior. The present study also examined the relationships between the Inventory of Learning Processes and both the sum of the two achievement scores and the difference between the two achievement scores (Achievement-via-Independence minus Achievement-via-Conformance). A high sum indicates that a high score on one achievement scale is coupled with a high score on the other. A high difference score indicates high Achievement-via-Independence coupled with low
Achievement-via-Conformance. Gough (1957) has provided a theoretical rationale for using these combined scores.

\section{Procedure}

The study was run in two one-hour sessions held one week apart. During the first session the students completed (in order) the Inventory of Learning Processes, the Scale of Academic Curiosity, The Questionnaire Upon Mental Imagery, and the Imagery Rating Scale. During the second session, they were administered (in order) the two achievement motivation scales (presented as a single scale), the Test Anxiety Questionnaire, and the Manifest Anxiety Scale. Students were debriefed at the end of the study and given an opportunity to ask questions regarding the goals and procedures of the study.

\section{Results and Discussion}

Since separate analyses of the data from male and female students revealed no sex differences, only the results of the combined analysis will be presented. Table 3 relates the scales of the Inventory of Learning Processes to the other scale scores. This table contains the simple zero-order correlation coefficients as well as the beta weights and multiple correlation coefficients obtained by deriving multiple regression equations using the scales of the Inventory of Learning Processes to predict the other scale scores. The beta weights provide an indication of the independence of the relationships.

As expected, both measures of mental imagery showed significant positive relationships with the Elaborative Processing Scale $(r=.26$ and .30$)$, suggesting that the list of elaborative information-processing techniques assessed by this scale does include mental imagery. It should be recalled that Ribich (1976) formerly demonstrated that the scale is also positively related to subjective organization. Although it is not indicated in Table 3, a detailed 


\begin{tabular}{|c|c|c|c|c|c|c|c|c|c|}
\hline \multirow{3}{*}{ Beta Weight } & \multicolumn{9}{|c|}{ ILP Scale } \\
\hline & \multicolumn{2}{|c|}{$\begin{array}{l}\text { Synthesis- } \\
\text { Analysis }\end{array}$} & \multicolumn{2}{|c|}{$\begin{array}{c}\text { Study } \\
\text { Methods }\end{array}$} & \multicolumn{2}{|c|}{$\begin{array}{c}\text { Fact } \\
\text { Retention }\end{array}$} & \multicolumn{2}{|c|}{$\begin{array}{l}\text { Elaborative } \\
\text { Processing }\end{array}$} & \multirow[b]{2}{*}{$\mathrm{R}$} \\
\hline & $r$ & $\mathrm{~b}$ & $r$ & $\mathrm{~b}$ & $r$ & $\mathrm{~b}$ & $r$ & $\mathrm{~b}$ & \\
\hline \multicolumn{10}{|l|}{ Academic } \\
\hline Curiosity & $28 * *$ & 11 & $49 * *$ & $42 * *$ & 13 & -07 & $36 * *$ & $20 *$ & $55 * *$ \\
\hline \multicolumn{10}{|l|}{ Achievement } \\
\hline $\begin{array}{l}\text { via Ind. (AI) } \\
\text { Achievement }\end{array}$ & $34 * \%$ & $38 * * x$ & 00 & -12 & 13 & 05 & 02 & -07 & $36 * *$ \\
\hline $\begin{array}{l}\text { Achievement } \\
\text { via Con. (AC) }\end{array}$ & $52 * *$ & $48 * *$ & $27 * \div$ & 09 & $24 * *$ & 06 & 18 & -02 & $54 * *$ \\
\hline$A I+A C$ & $50 * *$ & $51^{* *}$ & 16 & -01 & 23 & 06 & 09 & -05 & $52 * *$ \\
\hline$A I-A C$ & -19 & -15 & $-26 * *$ & $-21 *$ & -13 & -01 & -11 & -05 & $32 *$ \\
\hline \multicolumn{10}{|l|}{ Manifest } \\
\hline Anxiety & $-52 * *$ & $-47 * *$ & -19 & 01 & $-33 * *$ & -17 & -16 & 01 & $54 * *$ \\
\hline Test Anxiety & $-37 * *$ & $-39 * *$ & -16 & -09 & -18 & -01 & -03 & 10 & $41 * *$ \\
\hline $\begin{array}{l}\text { Betts Imagery } \\
\text { Imagery }\end{array}$ & 06 & -10 & $20 *$ & 13 & 13 & 12 & $26 * *$ & $24 *$ & $32 *$ \\
\hline Rating & -10 & $-21 *$ & 16 & 19 & -12 & -17 & $30 * *$ & $34 * *$ & $42 * *$ \\
\hline
\end{tabular}

Note. Decimal points have been omitted. $* \mathrm{p}<.05 ; * * \mathrm{p}<.01$

analysis of the data revealed that the greatest relationship occurred between Elaborative Processing and the visual imagery subscale of the Questionnaire Upon Mental Imagery $(r=.28)$. It is interesting that the multiple regression equation predicting scores on the Imagery Rating Scale yielded a significant negative beta weight for Synthesis-Analysis. Although Schmeck, Ribich, and Ramanaiah (1977) reported a significant relationship between Synthesis-Analysis and Elaborative Processing, this latter finding provides evidence regarding the differential validity of the two scales.

The two anxiety measures demonstrated the expected negative relationships with the Synthesis-Analysis scale $(r=-.52$ and -.37$)$. The beta weights indicated that a similar relationship with Fact Retention was not independent. Schwartz (1975) hypothesized that "arousal, indexed by personality measures, influences the way in which memory is organized. Specifically, high-arousal subjects focus on the physical aspects of verbal material, whereas lowarousal subjects organize memory around semantic cues" (p. 223). The finding of a negative relationship between anxiety and SynthesisAnalysis in the present study may be considered as further support for Schwartz's (1975) hypothesis as well as evidence in support of the view that the Synthesis-Analysis scale measures the degree of organized semantic processing to which the individual is prone. It is interesting to note once again that although they were related to Synthesis-Analysis, neither measure of anxiety was related to Elaborative Processing.

The zero-order correlation coefficients in Table 3 indicate that the Scale of Academic Curiosity was positively related to Synthesis- 
Analysis $(r=.28)$, Study Methods $(r=.49)$, and Elaborative Processing $(r=.36)$. These relationships were anticipated, but the multiple regression analyses indicated that the relationships were not all independent of one another. The beta weights in Table 3 indicate that the multiple correlation between the Inventory of Learning Processes and the Scale of Academic Curiosity $(R=.55)$ was attributable chiefly to the relationship between Study Methods and Academic Curiosity. Elaborative Processing also demonstrated a small but independent relationship with Academic Curiosity. Apparently, information seeking constitutes a large part of the activity assessed by the Study Methods scale and a small but significant part of that assessed by the Elaborative Processing scale.

In regard to the individual achievement motivation measures, it was predicted that Achievement-via-Independence would relate positively to Synthesis-Analysis and Elaborative Processing and Achievement-via-Conformance would relate positively to Study Methods and Fact Retention. Although the simple correlation coefficients lend some support to these predictions, the beta weights indicate that Synthesis-Analysis was the only learning process scale to show a unique relationship with either of the above achievement motivation measures.

Examination of the combined (sum and difference) achievement motivation scores revealed that Synthesis-Analysis was positively related to the sum of the achievement scores. In addition, Study Methods were negatively related to the difference between the achievement motivation scores. Since a high sum indicates simultaneously high scores on both achievement motivation scales, the positive correlation between this sum and Synthesis-Analysis supposedly indicates that those who score high on the latter scale are "efficient, mature, organized, and stable" (Gough, 1957, p. 9). Likewise, since a high difference score indicates relatively higher scores on Achievement-via-Independence than on Achievement-via-Conformance, the negative relationship between these difference scores and scores on Study Methods suggests that those who score high on Study Methods are "compliant, industrious, moderate, and quiet" (Gough, 1957, p. 9).

Table 4 presents the intercorrelations among those measures administered along with the Inventory of Learning Processes. It is worth noting some of the more interesting relationships. The intercorrelations among the achievement and anxiety measures essentially indicate that highanxiety students generally scored low on both achievement scales but scored relatively higher on Achievement-via-Independence than on Achievement-via-Conformance. This generalization is based upon the finding of a negative correlation between anxiety and the sum of the two achievement scales coupled with a positive correlation between anxiety and the difference between the two achievement scales. Table 3 also indicates positive relationships between the Scale of Academic Curiosity and both imagery measures, suggesting that more curious students have more imagery ability.

\section{SUMMARY AND CONCLUSIONS}

Scores on the Synthesis-Analysis scale were found to relate positively to those on the Critical Thinking Appraisal and to the sum of scores on the Conformance and Independence achievement scales of the California Psychological Inventory. Furthermore, scores on SynthesisAnalysis were inversely related to those on the Manifest Anxiety Scale, the Test Anxiety Questionnaire, and the Imagery Rating Scale. Thus, the individual who earns a high score on Synthesis-Analysis tends to be high on critical thinking ability and achievement motivation. The person also tends to be curious, efficient, mature, organized, stable, and low anxious. Furthermore, the negative relationship with anxiety supports the hypothesis that those who score high on Synthesis-Analysis pay attention to and are effective in dealing with semantic organization or structure and are concerned 
Table 4

Intercorrelations Among the Scales Administered Along with the Inventory of Learning Processes

\begin{tabular}{|c|c|c|c|c|c|c|c|c|}
\hline Scale & $\mathrm{AI}$ & $\underline{\mathrm{AC}}$ & $\mathrm{AI}+\mathrm{AC}$ & $\mathrm{AI}-\mathrm{AC}$ & $\begin{array}{l}\text { Mani. } \\
\text { Anxi. }\end{array}$ & $\begin{array}{l}\text { Test } \\
\text { Anxi. }\end{array}$ & $\begin{array}{l}\text { Betts } \\
\text { Imag. }\end{array}$ & $\begin{array}{l}\text { Imag. } \\
\text { Rate }\end{array}$ \\
\hline \multicolumn{9}{|l|}{ Academic } \\
\hline Curiosity & 03 & $29 * *$ & 16 & -19 & -11 & -14 & $26 * *$ & $23 *$ \\
\hline \multicolumn{9}{|l|}{ Achievement } \\
\hline $\begin{array}{l}\text { via Ind. (AI) } \\
\text { Achievement }\end{array}$ & & $46 * *$ & $85 * *$ & $45 * \pi$ & $-34 * *$ & $-21 *$ & $-22 *$ & -11 \\
\hline via Con. (AC) & & & $37 * *$ & $-56 * *$ & $-56 * *$ & $-45 * *$ & 00 & -01 \\
\hline $\mathrm{AI}+\mathrm{AC}$ & & & & -09 & $-55 * *$ & $-44 * *$ & -17 & -11 \\
\hline $\mathrm{AI}-\mathrm{AC}$ & & & & & $28 * *$ & $33 * *$ & -11 & -02 \\
\hline \multicolumn{9}{|l|}{ Manifest } \\
\hline Anxiety & & & & & & $59 * *$ & 02 & 02 \\
\hline Test Anxiety & & & & & & & 16 & -07 \\
\hline Betts Imagery & & & & & & & & $37 * *$ \\
\hline
\end{tabular}

Note. $\begin{aligned} & \text { Decimal points have been omitted. } \\ & x_{\mathrm{p}}<.05 \\ & *^{*} \mathrm{p}<\mathrm{0}<01\end{aligned}$

more with the meanings and implications of words than with the words themselves. This latter hypothesis is also supported by Ribich's (1976) finding that Synthesis-Analysis is positively related to note-taking efficiency. Malin and Malin (1976) have described a study procedure which seems to encourage students to engage in activities similar to those assessed by the Synthesis-Analysis scale.

The Study Methods scale was found to relate positively to the Scale of Academic Curiosity and negatively to the Critical Thinking Appraisal and to the scores produced by subtracting Achievement-via-Conformance from Achievement-via-Independence. Thus, it appears that the person who scores high on this scale tends to have a small amount of critical thinking ability but a large amount of academic curiosity. Furthermore, he or she tends to be compliant, industrious, moderate, and quiet. The authors feel that those who earn high scores on Study Methods study a lot but are prone to engage in repetitive rehearsal more often than elaborative rehearsal. This hypothesis is supported by Schmeck and Grove (1978) who reported that college grade-point-average is positively related to scores on Synthesis-Analysis but not to scores on Study Methods, suggesting that the activities assessed by Synthesis-Analysis are more likely to lead to real achievement in college. However, it should also be noted that Schmeck and Grove (1978) did report that Study Methods was a significant predictor of ACT examination scores.

The Fact Retention scale was not related to any of the other scales employed in the present studies. However, the authors assume that the scale assesses the activity of retaining details. It should be recalled that the scale was previously found to positively relate to objective test performance, college grade-point-average, and ACT examination scores (Ribich, 1976; Schmeck, Ribich, \& Ramanaiah, 1977; Schmeck \& Grove, 1978). 
The Elaborative Processing scale was positively related to the Scale of Academic Curiosity, Betts Questionnaire Upon Mental Imagery, and the Imagery Rating Scale. Thus, in addition to a positive relationship with subjective organization (Ribich, 1976), the Elaborative Processing scale also relates positively to imagery ability. It is assumed that this scale generally assesses the extent to which the individual codes information in terms of personal experiences. The scale seems to predict performance in verbal learning studies slightly better than in academic settings (Ribich, 1976; Schmeck, Ribich, \& Ramanaiah, 1977; Schmeck \& Grove, 1978).

\section{References}

Cameron, N. The psychology of behavior disorders. New York: Houghton Mifflin, 1947.

Craik, F. I. M. Depth of processing in recall and recognition. In S. Dornic (Ed.), Attention and performance (Vol. 6). Hillsdale, NJ: Lawrence Erlbaum Associates, 1977.

Craik, F. I. M., \& Lockhart, R. S. Levels of processing: A framework for memory research. Journal of Verbal Learning and Verbal Behavior. $1972,11,671-684$.

Craik, F. I. M., \& Tulving, E. Depth of processing and retention of words in episodic memory. Journal of Experimental Psychology: General, 1975. 104, 268-294.

Domino, G. Differential prediction of academic achievement in conforming and independent settings. Journal of Educational Psychology. 1968, 59, 256-260.

Domino, G. Interactive effects of achievement orientation and teaching style on academic achievement. Journal of Educational Psychology, $1971,62,427-431$.

Gough, H. G. Manual for the California Psychological Inventory. Palo Alto, CA: Consulting Psychologists Press, 1957.

Johnson, J. H. Memory and personality: An information-processing approach. Journal of $R e$ search in Personality, 1974, 8, 1-32.

Malin, J. T., \& Malin, D. H. Text comprehension and study skills: Final report. Unpublished manuscript, University of Houston, 1976.
Mandler, G., \& Sarason, S. B. A study of anxiety and learning. Journal of Abnormal and Social Psychology, 1952, 47, 166-173.

Marton, F., \& Saljo, R. On qualitative differences in learning: I. Outcome and process. British Journal of Educational Psychology, 1976, 46, 4-11.

Maw, W. H., \& Maw, E. W. Information recognition by children with high and low curiosity. Education Research Bulletin, 1961, 40, 197-201.

Paivio, A. Imagery and verbal processes. New York: Holt, Rinehart, \& Winston, 1971.

Paivio, A., Yuille, J. C., \& Madigan, S. Concreteness, imagery and meaningfulness values for 925 nouns. Journal of Experimental Psychology Monograph. 1968, 76 (1, Part 2), 1-25.

Pettigrew, T. F. The measurement and correlates of category width as a cognitive variable. Journal of Personality, 1958, 26, 532-544.

Ribich, F. D. Performance on word list and prose learning tasks as a function of learning style. Unpublished Master's thesis, Southern Illinois University, 1976.

Schmeck, R. R., \& Grove, E. Academic achievement and individual differences in learning processes. Unpublished manuscript, Southern Illinois University, 1978.

Schmeck, R. R., Ribich, F., \& Ramanaiah, N. Development of a self-report inventory for assessing individual differences in learning processes. Applied Psychological Measurement, 1977. $1,413-431$.

Schwartz, S. Individual differences in cognition: Some relations between personality and memory. Journal of Research in Personality. 1975, 9. 217-225.

Sheehan, P. W. A shortened form of Betts Questionnaire Upon Mental Imagery. Journal of Clinical Psychology, 1967, 23, 386-389.

Taylor, J. A. A personality scale of manifest anxiety. Journal of Abnormal and Social Psychology. 1953, $48,285-290$.

Tulving, E. Subjective organization in free recall of "unrelated" words. Psychological Review, 1962. 69, 344-354.

Vidler, D. C., \& Rawan, H. R. Construct validation of a scale of academic curiosity. Psychological Reports, 1974, 35, 263-266.

Vidler, D. C., \& Rawan, H. R. Further validation of a scale of academic curiosity. Psychological Reports, 1975, 37, 115-118.

Watson, G., \& Glaser, E. M. Watson-Glaser critical thinking appraisal manual. New York: Harcourt, Brace, \& World, 1964. 
Weinstein, C. E. Learning of elaboration strategies. Unpublished doctoral dissertation, University of Texas at Austin, 1975.

Weinstein, C. E. Cognitive elaboration learning strategies. Paper presented at the Annual Meeting of the American Educational Research Association, 1977.

Williams, C. A study of cognitive preference. The Journal of Experimental Education, 1975, 43. 61-77.

\section{Acknowledgements}

The Cognitive Preference Test used in Study 1 was used with permission of its author.

\section{Author's Address}

Ronald R. Schmeck, Department of Psychology, Southern Illinois University, Carbondale, IL 62901. 